\title{
Immune-Mediated Necrotizing Myopathy Is Characterized by a Specific Th1-M1 Polarized Immune Profile
}

\author{
Corinna Preuße, ${ }^{*}$ Hans H. Goebel, ${ }^{* \dagger}$ \\ Josephin Held, ${ }^{*}$ Oliver Wengert, ${ }^{\ddagger}$ \\ Franziska Scheibe, ${ }^{\ddagger}$ Kerstin Irlbacher, ${ }^{\ddagger}$ \\ Arend Koch, ${ }^{*}$ Frank L. Heppner, ${ }^{*}$ and \\ Werner Stenzel*

\begin{abstract}
From the Departments of Neuropathology* and Neurology, Charite-Universitätsmedizin, Berlin; and the Department of Neuropathology, ${ }^{\dagger}$ University Medicine, Johannes Gutenberg
\end{abstract} \\ University, Mainz, Germany
}

Immune-mediated necrotizing myopathy (IMNM) is considered one of the idiopathic inflammatory myopathies, comprising dermatomyositis, polymyositis, and inclusion body myositis. The heterogeneous group of necrotizing myopathies shows a varying amount of necrotic muscle fibers, myophagocytosis, and a sparse inflammatory infiltrate. The underlying immune response in necrotizing myopathy has not yet been addressed in detail. Affected muscle tissue, obtained from 16 patients with IMNM, was analyzed compared with eight non-IMNM (nIMNM) tissues. Inflammatory cells were characterized by IHC, and immune mediators were assessed by quantitative real-time PCR. We demonstrate that immune- and non-immune-mediated disease can be distinguished by a specific immune profile with significantly more prominent major histocompatibility complex class I expression and complement deposition and a conspicuous inflammatory infiltrate. In addition, patients with IMNM exhibit a strong type 1 helper T cell (T1)/classically activated macrophage M1 response, with detection of elevated interferon- $\gamma$, tumor necrosis factor- $\alpha$, IL-12, and STAT1 levels in the muscle tissue, which may serve as biomarkers and aid in diagnostic decisions. Furthermore, $B$ cells and high expression of the chemoattractant CXCL13 were identified in a subgroup of patients with defined autoantibodies. Taken together, we propose a diagnostic armamentarium that allows for clear differentiation between IMNM and nIMNM. In addition, we have characterized a Th1driven, M1-mediated immune response in most of the autoimmune necrotizing myopathies, which may guide therapeutic options in the future. (Am J Pathol 2012, 181: 2161-2171; bttp://dx.doi.org/10.1016/j.ajpath.2012.08.033)

Immune-mediated inflammatory myopathies (IIMs) comprise the classic inflammatory myopathies, dermatomyositis (DM), and polymyositis (PM). However, some researchers have expressed a critical view on PM as an entity, ${ }^{1,2}$ inclusion body myositis (IBM), and immune-mediated necrotizing myopathy (IMNM), ${ }^{3}$ recently also termed necrotizing autoimmune myositis. ${ }^{4,5}$ These diseases are defined as immune-mediated inflammatory myopathies, ${ }^{5}$ outnumbering other rare inflammatory myopathies, such as eosinophilic myofasciitis, granulomatous myositis, or macrophagic myofasciitis. They all share the classic symptoms of myalgia and muscle weakness, with each of them being characterized by specific clinical and morphological features. ${ }^{5,6} \mathrm{DM}$ and $\mathrm{PM}$ show a relatively good responsiveness to immunosuppressive therapies, whereas IBM, in general, displays a slower development of symptoms and shows no substantial response to immunosuppressive therapy. ${ }^{7-13}$ In addition to the widely accepted clinical classification, a new one has been presented recently that is based on pathological criteria of immune and inflammatory myopathies. In this classification, IMNM is described as immune polymyopathy containing myofiber necrosis, regeneration, and a poor mononuclear cell infiltrate with varying trans-sarcolemmal major histocompatibility complex (MHC) class I positivity. 1,14,15

Patients with subacute skeletal muscle weakness, myalgia, elevated serum creatine kinase levels, and an elec-

Supported by a grant from the The German Society for Muscular Dystrophy Association DGM (W.S.), the FAZIT Stiftung (C.P.), and Else KrönerFresenius-Stiftung (J.H.).

Accepted for publication August 30, 2012.

Supplemental material for this article can be found at http://ajp. amjpathol.org or at $h$ ttp://dx.doi.org/10.1016/j.ajpath.2012.08.033.

Address reprint requests to Werner Stenzel, M.D., Department of Neuropathology, Charité-Universitätsmedizin Berlin, Charité Campus Mitte, Charitéplatz 1, D-10117 Berlin, Germany. E-mail: werner.stenzel@ charite.de. 
tromyogram showing signs of muscle irritability may display NM on a muscle biopsy specimen. NM, be it IMNM or non-IMNM (nIMNM), can be encountered in a large variety of etiopathological contexts. ${ }^{16,17}$ Within the heterogeneous group of NMs, the immune-mediated ones are of particular interest, because they can potentially be amenable to immunosuppressive/immunomodulatory treatment. ${ }^{4,7,18}$ Clinically, patients with IMNM, in addition to the myalgia, proximal weakness, and high creatine kinase levels previously mentioned, manifest with additional symptoms, such as fever, cardiac or pulmonary involvement, and weight loss; these symptoms are generally not encountered in patients with nIMNM.

To our knowledge, the underlying molecular mechanisms of the immune response in IMNM have not been established. For the design of potential therapeutic approaches, it is of utmost importance to identify and understand the underlying pathogenic mechanisms. Corticosteroids are administered on a first-line basis by many clinicians, but their long-term use is problematic and evidence for more specific therapeutic approaches is lacking. ${ }^{3,12,19-21}$ Several new therapeutic attempts have been described in individual patients or small patient series. ${ }^{19,20,22,23}$

Similar to DM and PM, in which so-called myositisspecific antibodies and myositis-associated antibodies are important parts of the diagnostic approach, ${ }^{24,25}$ interesting specific autoantibodies have recently been described in IMNM. ${ }^{24-27}$ These autoantibodies compose the signal recognition particle (SRP), a ribonucleoprotein involved in the protein transport to the endoplasmatic reticulum, ${ }^{27,28}$ and the HMG-CoA antibody identified in a subgroup of immune-mediated statin-induced $\mathrm{NMs}^{29}$ which recently have been termed statin-induced necrotizing autoimmune myositis. ${ }^{4}$ Furthermore, patients with antibodies against antisynthetase antibodies (eg, Jo1, PL7, and PL12) and patients harboring autoantibodies associated with tumors, thus defining paraneoplasia (eg, anti-Ro or anti-Mi-2), appear to also show the classic pathomorphological picture of IMNM. ${ }^{24,30-34}$ There is evidence that involvement of the muscle is a secondary event to a primary autoimmune response against, for example, a tumor. ${ }^{35}$

In contrast to patients with IMNM, a toxic cause may also produce necrotizing myopathy, which, however, does not show additional clinical or morphological signs of a significant immune contribution. The latter cases need to be evaluated carefully (eg, toxicological screening and medical history) because the removal or cessation of the triggering agent will be mandatory for successful treatment. ${ }^{18,36}$ Also, a careful medical history about the duration of symptoms is of paramount significance.

Because immunosuppression/immunomodulation is useful in IMNM, ${ }^{3,27}$ the definition of a pathological concept may help to decide about putative therapeutic approaches and escalation in therapy.

In the present study, we aimed at identifying cellular and molecular characteristics of IMNM as opposed to those of nIMNM, to propose diagnostic tools, and molecular markers and mediators underlying the pathogenesis of IMNM and nIMNM.

\section{Materials and Methods}

\section{Patients and Biopsy Specimens}

Biopsy specimens of muscle tissue from 16 patients with IMNM, eight muscle samples from patients with nIMNM, and five skeletal muscle biopsy specimens from healthy control individuals were analyzed retrospectively. Based on the following different clinical parameters, we assigned patients with necrotizing myopathies to one of these groups. Assignment to the immune-mediated subgroup was based on at least one of the following parameters: myositis-specific autoantibodies, myositis-associated autoantibodies, autoantibodies associated with paraneoplastic disease, and/or defined autoimmune disease. In contrast, the non-immune-mediated subgroup did not display any autoantibodies or autoimmune disease or neoplasia. By definition, a causative toxic agent was identified in each patient with nIMNM, whereas none of the patients with IMNM received statins before the muscle biopsy was performed. Other conditions, such as muscular dystrophy (especially dystrophinopathy or dysferlinopathy), have been carefully excluded. Healthy controls constitute muscle biopsy specimens derived from neurologically healthy patients without any histological or ultrastructural abnormalities, including the absence of inflammatory infiltrates or MHC class I up-regulation and the absence of all relevant parameters associated with myositis (eg, autoantibodies and signs of systemic inflammation). Biopsy specimens were obtained from healthy control individuals because of diffuse myalgia. All procedures performed were single biopsies, and the analyzed area did not significantly differ between both groups [measured with an Olympus BX50 microscope and cell D software version 2.8 (Olympus, Hamburg, Germany); see Supplemental Figure S1 at http://ajp.amjpathol.org]. The entire section of each biopsy specimen was analyzed. The available clinical information is given in Table 1 and Supplemental Table S1 (available at $h t t p: / /$ ajp.amjpathol.org). Informed consent was obtained from all patients, and the Charite ethics committee has approved the study (approval number EA1/204/11). All muscle biopsy specimens were cryopreserved immediately after removal at $-80^{\circ} \mathrm{C}$ before diagnostic workup.

\section{Histological, Enzyme Histochemical, and IHC Studies}

The cryostat sections (7 $\mu \mathrm{m}$ thick) were stained with routine H\&E, modified Gömöri trichrome, Elastica van Gieson, PAS, PAS after diastase digestion, ATPase at $\mathrm{pH}$ 4.3, 4.6, and 9.4, acid phosphatase and nonspecific esterase, NADH tetrazolium reductase, succinic dehydrogenase, cytochrome $c$ oxidase, and alkaline phosphatase. The immunohistochemical $(\mathrm{IHC})$ demonstration of cells expressing CD4, CD8, CD11b, CD19, CD20, CD31, CD45/leukocyte common antigen, CD68, CD79a, CD138, deposition of complement C5b9 [membrane attack complex (MAC)], endothelial staining of factor VIII (von-Willebrand factor), expression of MHC class I on the sarcolemma, and IHC presentation of CD56 (neural cell 
Table 1. Clinical Findings of 24 Patients with Necrotizing Myopathy and Five Healthy Patients as Normal Controls

\begin{tabular}{|c|c|c|c|c|c|c|}
\hline Patient no. & $\begin{array}{c}\text { Age } \\
\text { (years) }\end{array}$ & Sex & $\begin{array}{l}\text { Time since onset } \\
\text { of symptoms } \\
\text { (months) }\end{array}$ & $\begin{array}{l}\text { CK level } \\
\text { (times fold) }\end{array}$ & Autoantibody (MAA/MSA) & Variable* \\
\hline \multicolumn{7}{|c|}{ IMNM Group } \\
\hline 1 & 57 & F & ND & 14 & $\begin{array}{c}\text { ANA 1:1280, PL7, PL12, Ro, } \\
\text { Ku, Ro52 }\end{array}$ & + \\
\hline 2 & 74 & M & 1 & 5 & - & + \\
\hline 3 & 80 & $\mathrm{~F}$ & 24 & 10 & ND & + \\
\hline 4 & 36 & $\mathrm{~F}$ & 13 & 46 & Ro52 & - \\
\hline 5 & 66 & M & ND & 41 & SRP & + \\
\hline 6 & 57 & M & 1 & ND & ASMA & + \\
\hline 7 & 19 & $\mathrm{~F}$ & 2 & 78 & SRP & - \\
\hline 8 & 55 & M & $>12$ & 47 & ND & + \\
\hline 9 & 63 & $\mathrm{~F}$ & 4 & ND & SRP & + \\
\hline 10 & 37 & $\mathrm{~F}$ & 22 & ND & ANA 1:2560, Ro52 & - \\
\hline 11 & 64 & $\mathrm{~F}$ & ND & 35 & Jo1 & + \\
\hline 12 & 79 & M & ND & 2.4 & AChR & + \\
\hline 13 & 68 & $\mathrm{~F}$ & 1 & 71 & Jo1 & + \\
\hline 14 & 37 & $\mathrm{~F}$ & 1.5 & 51 & Jo1 & + \\
\hline 15 & 71 & M & 0.75 & 45 & - & + \\
\hline 16 & 47 & M & 1.5 & 5 & - & + \\
\hline \multicolumn{7}{|c|}{ nIMNM } \\
\hline 17 & 52 & $\mathrm{~F}$ & ND & 33 & ND & Malarone \\
\hline 18 & 62 & M & 1 & 90 & - & $\begin{array}{l}\text { Statins, cyclosporine, } \\
\text { voriconazole }\end{array}$ \\
\hline 19 & 55 & $\mathrm{~F}$ & 12 & 15 & - & Statins \\
\hline 20 & 76 & M & 0.25 & 900 & ND & $\begin{array}{l}\text { Acute renal failure, dialysis, } \\
\text { diabetes }\end{array}$ \\
\hline 21 & 53 & $\mathrm{~F}$ & 12 & 50 & - & Quetiapine $^{\dagger}$ \\
\hline 22 & 75 & $\mathrm{~F}$ & $\sim 2$ & 300 & - & Statins \\
\hline 23 & 33 & M & 2 & 36 & ND & Alcohol excess \\
\hline 24 & 70 & $\mathrm{~F}$ & 1 & 93 & ND & Statins \\
\hline \multicolumn{7}{|c|}{ Healthy Control Group } \\
\hline 25 & 47 & M & - & Normal & - & $\begin{array}{l}\text { Diffuse myalgia and } \\
\text { arthralgia }\end{array}$ \\
\hline 26 & 41 & $\mathrm{~F}$ & - & Normal & - & Myalgia \\
\hline 27 & 2 & M & - & Normal & - & $\ddagger$ \\
\hline 28 & 57 & $\mathrm{~F}$ & - & Normal & - & Myalgia \\
\hline 29 & 55 & M & - & Normal & - & Myalgia and collagenosis \\
\hline
\end{tabular}

Grouped for immune-mediated (16 patients), non-immune-mediated ( 8 patients), and control (5 patients). For further specified information about the systemic disease and treatment, see Supplemental Table S1 (available at http://ajp.amjpathol.org).

${ }^{*}$ For IMNM, systemic disease (autoimmune or paraneoplastic) is listed as present or absent; for nIMNM, toxic agent/clinical aspect is listed; and for healthy controls, symptoms are listed.

†Recent change in antipsychotic treatment concomitant with onset of muscle symptoms.

${ }^{\ddagger}$ Mother with a history of malignant hyperthermia; therefore, due to an upcoming operation of the heart in her child, the risk for malignant hyperthermia in the child was excluded, among other means by doing a muscle biopsy which was entirely normal.

F, female; M, male; AChR, acetylcholine receptor; ANA, antinuclear antibodies; ASMA, $\alpha$-smooth muscle actin; MAA, myositis-associated antibody; MSA, myositis-specific antibody; ND, no data available; +, present; -, absent.

adhesion molecule), MHC neonatal, and $\alpha \mathrm{B}$ crystallin (Table 2) was performed by using the iview-Ventana DAB Detection Kit (Ventana, Tucson, AZ). Appropriate biotinylated secondary antibodies and diaminobenzidine visualization of the peroxidase reaction product on a Benchmark XT immunostainer (Ventana) in a standardized manner were used. Omission of primary antibodies in control sections resulted in absence of any cellular labeling.

For immunofluorescence, the sections were blocked with the appropriate serum (1:10 in PBS), dependent on the source of the secondary antibody and incubated with the previously mentioned primary antibodies overnight at $4^{\circ} \mathrm{C}$. After a washing step, the secondary antibody was added for 1 hour. For double immune staining, the same protocol was repeated with a second primary antibody and an ap- propriate secondary antibody. After a final washing step, the sections were mounted and stored at $4^{\circ} \mathrm{C}$. Photomicrographs were taken with the Zeiss Observer.Z1 Microscope (immunofluorescence), Axiovision software version 4 (Zeiss, Oberkochen, Germany), or the Olympus BX50 microscope, the digital camera DP25, and cell D software.

\section{Semiquantitative Scale and Cell Counts}

We defined a semiquantitative scale to compare IMNM with nIMNM. All cases were graded from 0 (none) to 4 (maximum), based on different histological stainings, and characterized two times in a blinded manner by three independent myopathologists (W.S., H.H.G., C.P.). The mean values from both scaling rounds are displayed. 
Table 2. Source of Primary Antibodies Used for IHC and Immunofluorescent Studies

\begin{tabular}{lllll}
\hline \multicolumn{1}{c}{ Antibody } & \multicolumn{1}{c}{ Type, species } & \multicolumn{2}{c}{ Clone } & \multicolumn{1}{c}{ Company } \\
\hline$\alpha$ B-crystallin & Monoclonal, mouse & G2JF & Novocastra (Wetzlar, Germany) \\
CD4 & Monoclonal, rabbit & SP35 & Zytomed Systems (Berlin, Germany) & Undiluted \\
CD8 & Monoclonal, mouse & C8/144B & Dako (Hamburg, Germany) & $1: 100$ \\
CD11b & Monoclonal, mouse & SP2/0 & Novacastra & $1: 20$ \\
CD19 & Monoclonal, mouse & LE-CD19 & Zytomed & $1: 100$ \\
CD20 & Monoclonal, mouse & L26 & Dako & $1: 400$ \\
CD31 & Monoclonal, mouse & JC70A & Dako & Undiluted \\
CD45 & Monoclonal, mouse & 2B11 and PD7/26 & Dako & $1: 400$ \\
CD79a & Monoclonal, mouse & JCB117 & Dako & $1: 100$ \\
CD206 & Monoclonal, mouse & T-450 & Acris Antibodies (Herford, Germany) \\
CD56 (NCAM) & Monoclonal, mouse & ERIC-1 & AbD Serotec (Düsseldorf, Germany) & $1: 100$ \\
CD68 & Monoclonal, mouse & KP1 & Dako & $1: 200$ \\
MHC class I & Monoclonal, mouse & W6/32 & Dako & $1: 10,000$ \\
MHC neonatal & Monoclonal, mouse & WB-MHC neonatal & Novocastra & $1: 1000$ \\
CD138 & Monoclonal, mouse & Ml15 & Dako & $1: 20$ \\
C5b9 & Monoclonal, mouse & aE11 & Dako & $1: 30$ \\
Factor VIII & Polyclonal, rabbit & NA & Dako & $1: 200$ \\
\hline
\end{tabular}

NA, not applicable.

The scale for MHC class I expression was defined as follows: 0 , no sarcolemmal staining; $1,>10 \%$ of fibers with sarcolemmal staining; $2,>30 \%$ of fibers with sarcolemmal staining; $3,>60 \%$ of fibers with sarcolemmal staining and scant sarcoplasmic staining; and 4, >90\% of fibers with sarcolemmal and strong sarcoplasmic staining (see Supplemental Figure S2 at http://ajp.amjpathol.org).

The scale for C5b9 complement (MAC) deposition was defined as follows: 0 , no capillaries stained; $1,>10 \%$ of capillaries (some or few); $2,>30 \%$ of capillaries (focal); $3,>60 \%$ of capillaries (large areas); and $4,>90 \%$ of capillaries show MAC deposition.

CD56- and MHC neonatal-positive fibers were scored as follows: 0 , no fibers stained; $1,>10 \%$ of fibers stained; $2,>30 \%$ of fibers stained; $3,>60 \%$ of fibers stained; and $4,>90 \%$ of fibers stained.

For quantification of $\mathrm{CD} 4^{+}$or $\mathrm{CD} 8^{+} \mathrm{T}$ cells, $\mathrm{CD} 2 \mathrm{O}^{+}$or $\mathrm{CD} 79 \mathrm{a}^{+} \mathrm{B}$ cells, CD138 ${ }^{+}$plasma cells, and $\mathrm{CD}^{+} 8^{+}$macrophages, we performed cell counts of 10 high-power fields (one high-power field is defined as $0.16 \mathrm{~mm}^{2}$ ) of each biopsy specimen. The average number of cells per high-power field per case is displayed.

\section{Electron Microscopy}

Ultrastructural analysis of all muscle specimens was performed routinely after fixation in $2.5 \%$ glutaraldehyde for 48 hours at $4^{\circ} \mathrm{C}$, post fixation in $1 \%$ osmium tetroxide, and embedding in araldite. Ultrathin sections were stained with uranyl acetate and lead citrate, after three to five blocks were generated from each sample. Electron microscopy was performed with a Zeiss P902 electron microscope.

\section{Real-Time qPCR}

Total RNA was extracted from the muscle tissue samples using the TRIzol/chloroform method, according to the manufacturer's instruction (Invitrogen, Carlsbad, CA). Thereafter, RNA was resuspended in $60 \mu \mathrm{L}$ of diethylpyrocarbonate-treated water and the concentration of total RNA was photometrically determined with a TECAN fluorescence plate reader (Tecan, Männedorf, Switzerland). The RNA was reverse transcribed using the HighCapacity cDNA Archive Kit (Applied Biosystems, Foster City, CA), according to the manufacturer's protocol, by using 1 or $2 \mu \mathrm{g}$ of total RNA per sample, as described. ${ }^{37}$

The expression levels of gene transcripts and of the endogenous control gene, phosphoglycerate kinase 1 (PGK1), were analyzed in the specimens by quantitative real-time RT-PCR using the $5^{\prime}$-nuclease technology on an ABI PRISM 7900HT Sequence Detection System and the human TaqMan predeveloped assay reagents (both from Applied Biosystems). The expression level of the housekeeping gene PGK1 was similar in all analyzed samples and unaffected by duration of the diseases. The assay identification numbers are as follows: IL-4, Hs00929862_m1; IL-4 receptor, Hs00166237_m1; IL-13, Hs99999038_m1; CD206, Hs00267207_m1; inducible nitric oxide synthase (iNOS), Hs01075529_m1; interferon (IFN)- $\gamma$, Hs00989291_m1; tumor necrosis factor (TNF)- $\alpha$, Hs00174128_m1; IL-12p40, Hs01011518_m1; cyclooxygenase 2, Hs00153133_m1; CXCL13, Hs00757930_m1; STAT1, Hs01013989_m1; and PGK, Hs99999906_m1.

The quantitative PCR (qPCR) reactions were prepared in a final volume of $20 \mu \mathrm{L}$, with the TaqMan Fast Universal PCR Master Mix (Applied Biosystems), containing $20 \mathrm{ng}$ of CDNA. All analyses were performed in triplicate, and the $\mathrm{C}_{\mathrm{T}}$ was determined. Data display the reciprocal $\Delta \mathrm{C}_{\mathrm{T}}$ to show gene expression of the respective markers of the two groups of NM compared with healthy controls.

\section{Statistics}

For analysis of the semiquantitative score of histological stainings, we used the U-test. Furthermore, the KruskalWallis one-way analysis of variance with Bonferroni correction was applied for analysis of quantitative differences of mRNA transcripts. It was not possible to perform statistics with the Kruskal-Wallis test for the expression of 


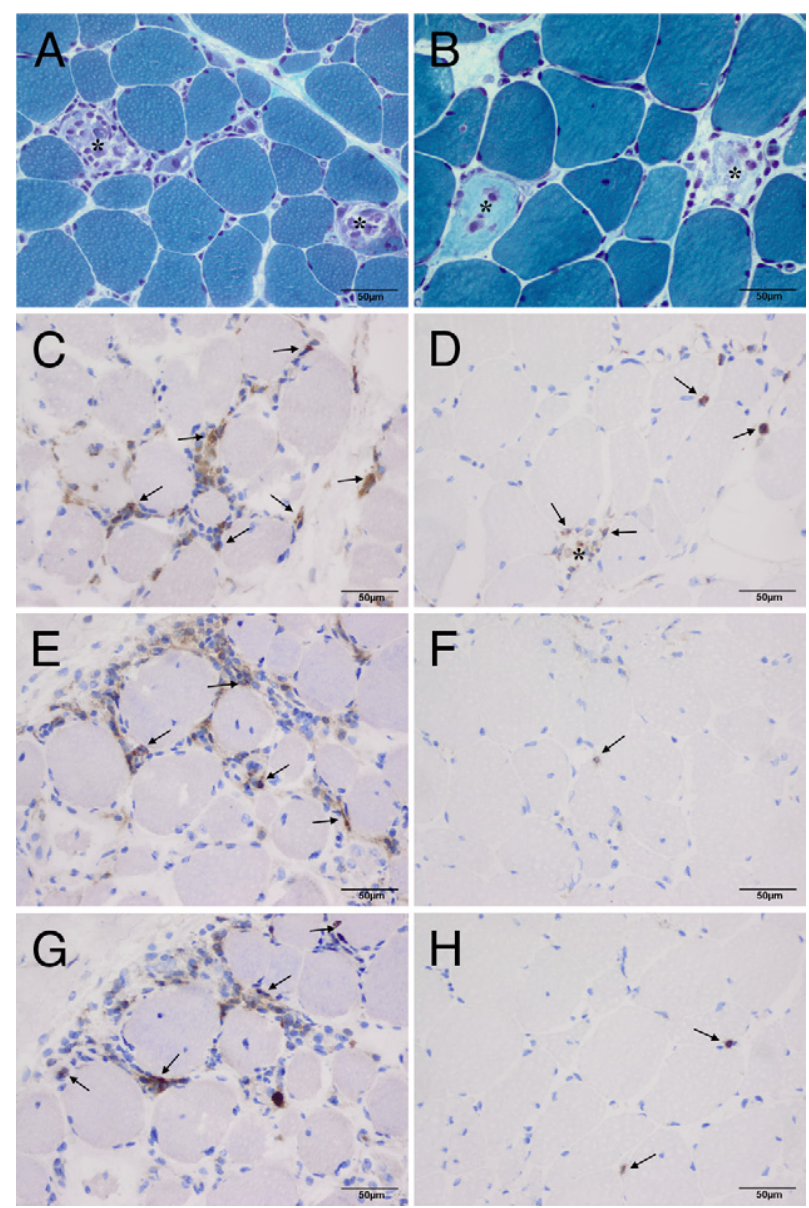

Figure 1. Morphological characterization of both subgroups with necrotizing myopathy by Gömöri trichrome staining of IMNM and nIMNM shows myophagocytosis and necrosis of muscle fibers (A and $\mathbf{B})$. Significantly more CD $68^{+}$macrophages $(\mathbf{C}$ and $\mathbf{D}), \mathrm{CD}^{+}$cells $(\mathbf{E}$ and $\mathbf{F})$, and $\mathrm{CD}^{+} \mathrm{T}$ cells $(\mathbf{G}$ and $\mathbf{H})$ are found in IMNM $(\mathbf{A}, \mathbf{C}, \mathbf{E}$, and $\mathbf{G})$ versus nIMNM $(\mathbf{B}, \mathbf{D}, \mathbf{F}$, and $\mathbf{H})$. Arrows, immunoreactive cells of the respective subtype; asterisk, necrotic muscle fiber. Original magnification, $\times 400$.

IL-12, IL-4, and IL-13, because the respective cytokines were not expressed in healthy controls. Data are presented as means with SDs. The level of significance was set at $P<0.05$. Statistics were calculated with GraphPad Prism software version 5.02 (GraphPad Software, Inc., San Diego, CA).

\section{Results}

\section{Analysis of Clinical Data}

To differentiate IMNM from nIMNM, we analyzed the clinical data of the patients enrolled in the study to identify similarities or differences between the two groups (Table 1). By definition, a causative toxic agent was identified in each patient with nIMNM; in some cases, it was likely that statins had induced the disease. None of these cases showed signs of an autoimmune-mediated process, because $\mathrm{MHC}$ class I up-regulation or complement deposition, criteria defined by Christopher-Stine et al, ${ }^{26}$ were not present.

There was no significant difference in the average age of the patients in both groups. In IMNM, the mean age was
$56.9 \pm 16.9$ years; and in nIMNM, $59.5 \pm 13.4$ years. In addition, the female/male ratio was not different between IMNM and nIMNM (both, 60:40). Furthermore, we observed higher creatine kinase levels and a shorter duration between admission to the hospital and onset of disease in patients with nIMNM compared with IMNM (Table 1).

\section{Patients with IMNM Exhibit a Prominent Expression of MHC Class I Molecules and Conspicuous Deposition of Complement on Capillaries in Skeletal Muscle}

It may be difficult to distinguish IMNM from nIMNM by routine histochemical staining (Figure 1, A and B). Therefore, additional IHC and ultrastructural analyses were of substantial help.

In the past, conflicting results regarding the expression of $\mathrm{MHC}$ class I molecules in muscle biopsy specimens derived from patients with necrotizing myopathies were reported. Although some studies showed no signs of MHC class I expression, ${ }^{27}$ others described at least some immunoreactivity on myofibers. ${ }^{19,26,28,38}$ In the present series, we demonstrated that skeletal muscle tissue from patients with IMNM displayed ample and

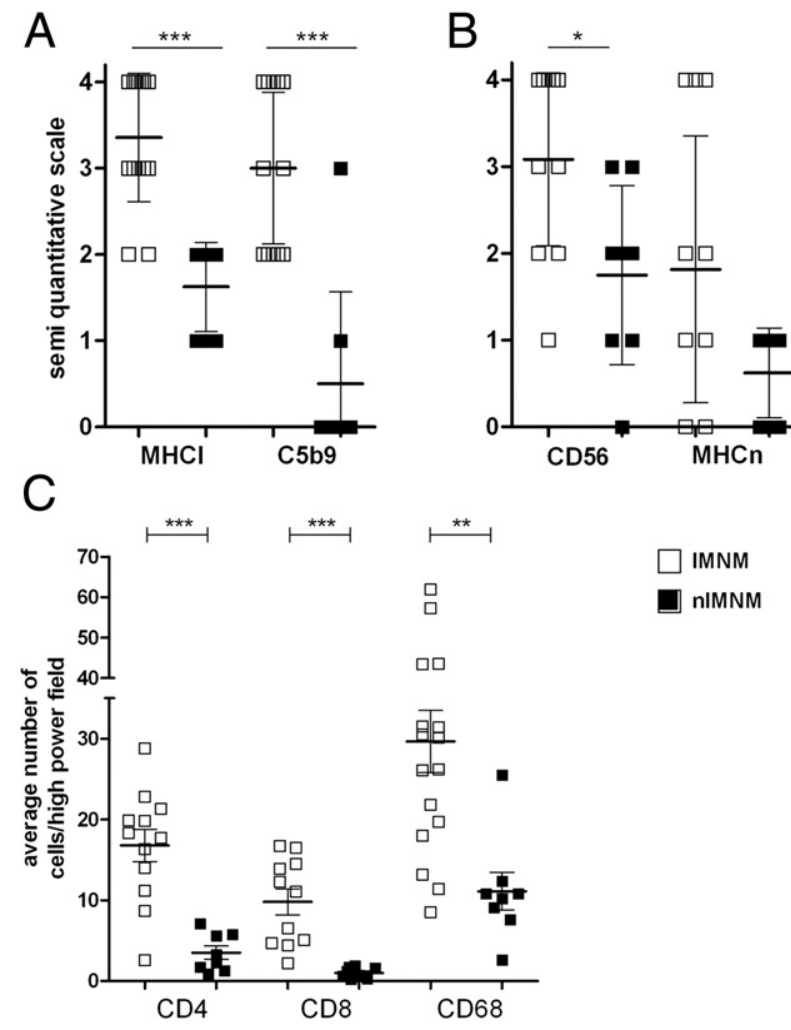

Figure 2. Illustration of a semiquantitative scale based on histological staining and cell counts; patients with IMNM and nIMNM are visualized as open and closed squares, respectively; sarcolemmal MHC class I expression and endothelial complement deposition (A), and regeneration of muscle fibers (B), are elevated in IMNM compared with nIMNM. Significantly more CD68 ${ }^{+}$ macrophages and $\mathrm{CD}^{+}$and $\mathrm{CD}^{+}$lymphocytes $(\mathbf{C})$ can be quantified in IMNM. A definition of the scale is given in Materials and Methods $(0$, minimum; 4, maximum). For cell count, the average number of cells per 10 high-power fields is shown. Data are given as mean with $\mathrm{SD} .{ }^{*} P<0.05$, ${ }^{* *} P<0.01$, and ${ }^{* * *} P<0.001$ 

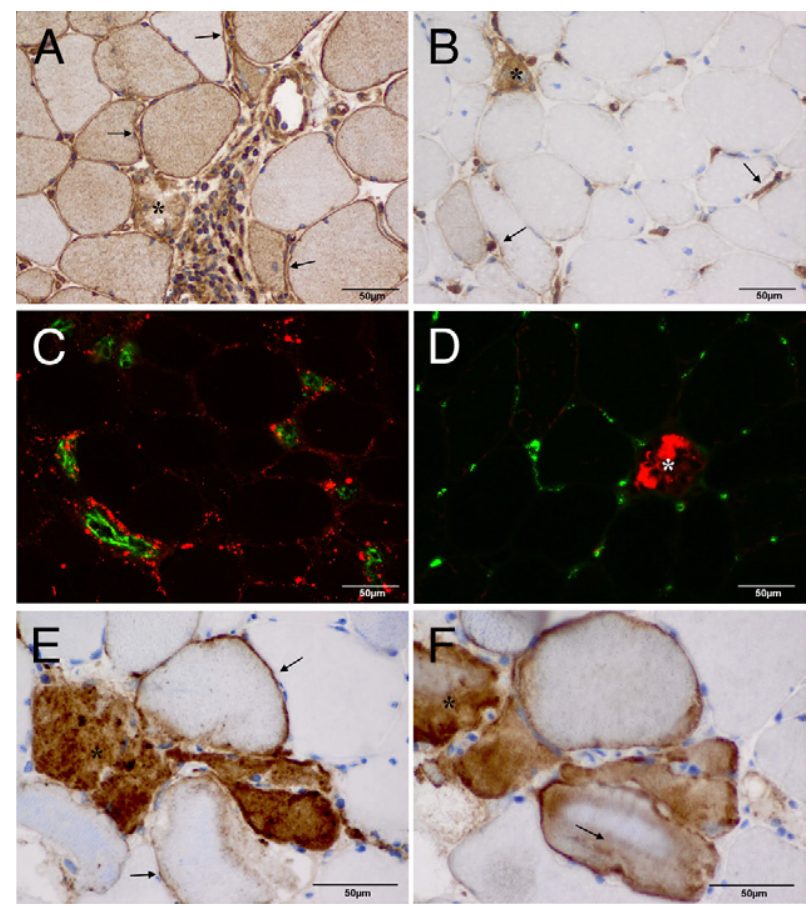

Figure 3. Trans-sarcolemmal MHC class I expression ( $\mathbf{A}$ and $\mathbf{B}$ ) is more prominent in an IMNM biopsy specimen compared with a representative nIMNM specimen. $\mathbf{C}$ and $\mathbf{D}$ : Double immunofluorescence illustrates important complement (MAC; C5b9) deposition (red) on endomysial capillaries stained by factor VIII (green) in IMNM, whereas nIMNM capillaries do not show complement deposition; a necrotic fiber (red) is stained in the center of the photomicrograph (D). In addition, sarcolemmal decoration of muscle fibers with complement C5b9 (E) in an IMNM case coincides with sarcoplasmatic $\alpha$ B-crystallin staining, indicating $\mathrm{X}$ fibers (F). Arrows, immunoreactivity; asterisks, necrotic muscle fiber.

intense trans-sarcolemmal immunoreactivity of $\mathrm{MHC}$ class I molecules on many nonnecrotic muscle fibers (Figures 2A and 3A). MHC I expression was diffusely distributed and particularly strong in biopsy specimens derived from patients with anti-SRP antibodies, antisynthetase syndrome with respective autoantibodies, and paraneoplastic necrotizing myopathies. A perifascicular pattern of atrophic fibers, such as in DM, was not a feature of IMNM, nor was a gradient of increasing capillary density toward the center of the fascicles. An electron microscopic investigation excluded the presence of tubuloreticular formations, which are characteristic of DM, in endothelial cells of IMNM muscle. In contrast, muscle biopsy specimens from patients with nIMNM showed MHC class I expression confined only to the sarcoplasm of necrotic fibers, and a scant sarcolemmal staining pattern on a few adjacent fibers. None of the nIMNM biopsy specimens showed a significant or diffuse up-regulation of $\mathrm{MHC}$ class I molecules on nonnecrotic fibers (Figures 2A and 3B).

Furthermore, complement deposition of MAC (C5b9) was particularly prominent in IMNM biopsy specimens, especially in patients with anti-SRP autoantibodies and antisynthetase syndrome, and in biopsy specimens derived from patients with a paraneoplastic cause with severe general systemic signs of disease (Figures 2A and 3C). In contrast, complement deposition on capillaries in the nIMNM group was insignificant or completely absent
(Figures 2A and 3D). In addition to the previously mentioned complement deposition on capillaries that was also previously described, ${ }^{1}$ an interesting and discriminating feature of severe IMNM cases was the decoration of the sarcolemma of nonnecrotic fibers by MAC (Figure $3 \mathrm{E})$. This feature was consistently absent in biopsy specimens derived from patients with nIMNM (data not shown). In addition, in IMNM muscle samples, we identified some of these fibers as so-called $X$ fibers, ${ }^{39}$ characterized by their labeling with $\alpha \mathrm{B}$ crystallin in the sarcoplasm (Figure 3F); they appeared otherwise normal by trichrome stain (Figure 1, A and B). This might indicate that these $X$ fibers were committed to be attacked by the immune system. ${ }^{39} X$ fibers were consistently absent in nIMNM specimens (data not shown).

\section{IMNM Skeletal Muscle Biopsy Specimens Are Characterized by a $\mathrm{CD} 4^{+}$and $\mathrm{CD} 8^{+} \mathrm{T}$-Cell Infiltrate}

Many researchers believed that IMNM, especially SRPassociated NM, was characterized by a poor cellular infiltrate. Therefore, we thoroughly investigated the presence and specific distribution of interstitial immune cells on serial sections in our samples using cell counts.

Quantitatively, $\mathrm{CD}^{+} 8^{+}$macrophages clearly constituted the dominant mononuclear cellular infiltrate. Biopsy specimens derived from patients with IMNM displayed many $\mathrm{CD}^{+} 8^{+}$macrophages in the endomysium and perimysium, independent of myophagocytosis, whereas in nIMNM, $\mathrm{CD} 8^{+}$macrophages were exclusively confined to necrotic fibers that underwent myophagocytosis (Figures 1, C and $\mathrm{D}$, and $2 \mathrm{C}$ ). In IMNM, a perimysial and endomysial inflammatory infiltrate consisting of $\mathrm{CD}^{+}{ }^{+}$(Figures $1, \mathrm{E}$ and $\mathrm{F}$, and 2C) and $\mathrm{CD}^{+}$(Figures 1, G and $\mathrm{H}$, and 2C) $\mathrm{T}$ cells was identified. In some cases, $T$ cells were also identified in a perivascular location, but necrotizing vasculitis was not a feature in IMNM biopsy specimens. In contrast, nIMNM biopsy specimens displayed only scant $T$ cells in the endomysium and in proximity to fiber necrosis and myophagocytosis (Figures 1, D, F, and $\mathrm{H}$, and $2 \mathrm{C}$ ).

We hypothesized that regenerating processes would differ in the muscle biopsy specimens derived from patients of either subgroup. Antibodies against neural cell adhesion molecule (CD56) and myosin heavy chain neonatal were used to identify these fibers. We found significantly more pronounced regeneration in IMNM, as indicated by the presence of numerous myosin heavy chain neonatal-positive fibers and neural cell adhesion molecule-positive (CD56) muscle fibers, whereas in biopsy specimens from patients with nIMNM, these antibodies were less frequently detected (Figure 2B; see also Supplemental Figure S3 at http://ajp.amjpathol.org).

\section{B Cells and Prominent B-Cell Chemoattraction Are Features of a Subgroup of IMNM Biopsy}

\section{Specimens}

As a trial, B-cell depletion therapy with rituximab was used in a few severely ill patients with SRP-autoantibody- 

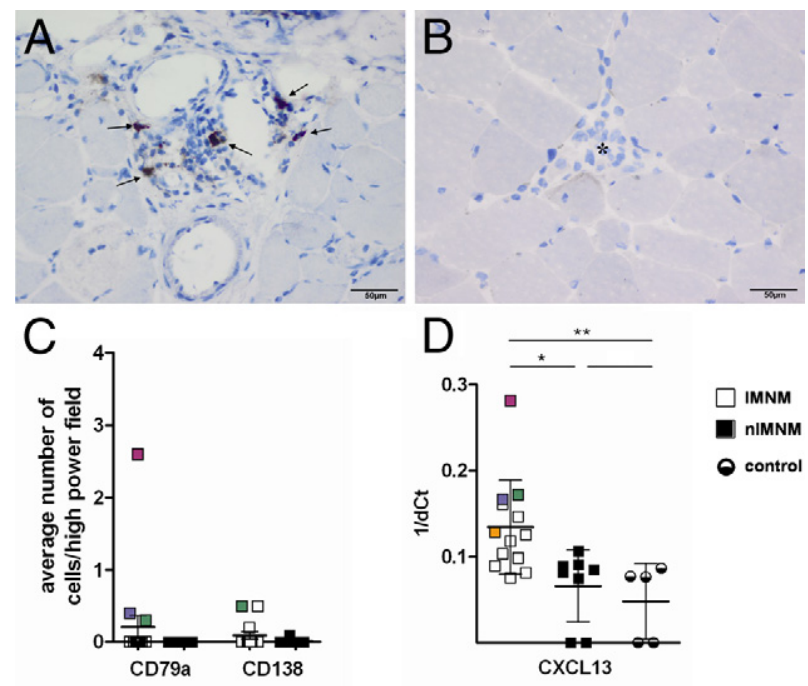

Figure 4. Illustration of $\mathrm{CD} 79 \mathrm{a}^{+} \mathrm{B}$ cells in IMNM (A) versus nIMNM (B) Quantification reveals more B cells (CD79a) and plasma cells (CD138) in immune-mediated cases $(\mathbf{C})$. The expression of the B-cell chemoattractant CXCL13, by qPCR is illustrated (D). Some patients with conspicuous B-cell infiltration also show highly increased expression levels of CXCL13 (marked by colored squares: blue and orange, Jo1 patients; green and purple, SRP patients). Statistics are performed with the $U$-test $(\mathbf{C})$ and the Kruskal-Wallis test (D). ${ }^{*} P<0.05,{ }^{* *} P<0.01$. Arrows, immunoreactivity for CD79a; asterisk, necrotic muscle fiber. ns, not significant.

mediated IMNM, which did not respond to corticosteroid therapy. ${ }^{4,40-42}$ In the present study, we aimed to define molecular markers of B-cell invasion of skeletal muscle during the immune process in IMNM. Of the 16 muscle biopsy specimens, three showed few, but conspicuous, amounts of $\mathrm{CD}_{19}{ }^{+}, \mathrm{CD}_{20}{ }^{+}$, or $\mathrm{CD}_{79} \mathrm{a}^{+} \mathrm{B}$ cells and one showed single CD138+ plasma cells in the endomysium, whereas the nIMNM biopsy specimens did not display any striking numbers of $B$ or plasma cells (Figure $4, A-C$ ). Interestingly, molecular analysis of the B-cell chemoattractant, CXCL13, ${ }^{43-45}$ in the muscle biopsy specimens revealed significantly higher expression of this chemokine in IMNM compared with those in nIMNM. Furthermore, most of the histologically proven biopsy specimens with B-cell invasion showed highly increased expression of CXCL13. One of these patients had Jo1 syndrome and two had SRP-associated myopathy (Figure 4, C and D).

\section{Immune Response in IMNM Is Essentially Characterized by Th1-M1 Mediators}

Based on our quantitative analysis of inflammatory mononuclear infiltrates in the IMNM biopsy specimens, we hypothesized that the immune response was essentially T-cell mediated and that the interaction between $T$ cells and macrophages played an important role in disease pathogenesis and progression. To specify the immune response, we analyzed key Th1 and Th2 markers by quantitative real-time PCR, and mediators of macrophage polarization, for classic or alternative activation status phenotypes. ${ }^{46-49}$ In contrast to nIMNM, IMNM was characterized by a significant up-regulation of the Th1 master cytokine, IFN- $\gamma$. Consequently, and in keeping with this finding, the cytokines TNF- $\alpha$ and IL-12 and the transcription factor STAT1 ${ }^{46,48-50}$ were significantly upregulated compared with healthy controls. In nIMNM samples, the respective Th1 cytokines were expressed at significantly lower levels (Figure 5, A and B).

However, the effector molecules, iNOS and cyclooxygenase 2, were not differentially regulated in either group, which may mirror comparable cytotoxic activities of macrophages in both groups (see Supplemental Figure S4 at http://ajp.amjpathol.org). A significant Th2 response, as measured by the expression of the master cytokines IL-4 and IL-13, was not detected (Figure 5C). Furthermore, expression of the common IL-4 receptor $\alpha$ (CD124), which mediated IL-4 and IL-13 signaling, and expression of the macrophage mannose receptor (CD206) were expressed at similar levels in both groups (Figure 5D).

\section{Discussion}

In addition to the classic entities, PM, DM, and sporadic IBM, IMNM is a further and important subgroup of immune-mediated myopathies. In this study, we defined molecular markers that help to delineate IMNM as a distinct entity, which can potentially be targeted by immunosuppressive/immunomodulatory therapy. In addition, we provide evidence that IMNM is essentially a Th1-M1mediated disease in which high levels of IFN- $\gamma$, TNF- $\alpha$, $\mathrm{IL}-12$, and STAT1 functionally regulate the immune re-
A

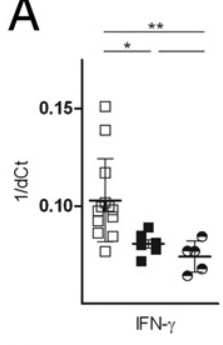

\section{C}

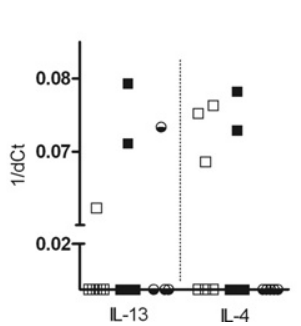

B

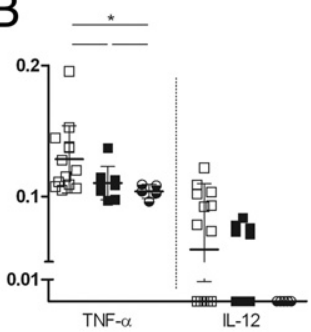

D

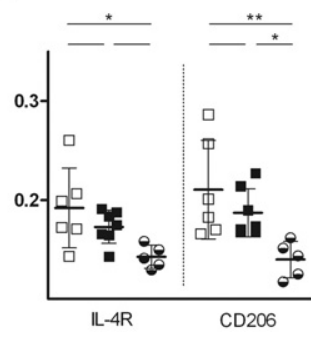

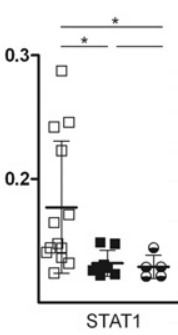

STAT1
Figure 5. Illustration of quantitative real-time measurements (qPCR) in IMNM and nIMNM: cytokines driven by the Th1 pathway (A) and markers of classically activated macrophages (B) are significantly up-regulated in IMNM compared with healthy controls, and compared with nIMNM in case of IFN- $\gamma$ and STAT1. The respective cytokines measured in nIMNM specimens compared with healthy controls do not differ. The Th2 cytokines IL-4 and IL-13 are, if at all detectable, expressed at low levels in all groups $(\mathbf{C})$; expression of the M2 markers CD206 and IL- 4 receptor (IL-4R) $\alpha$ (CD124) is on the same level in immune- and non-immune-mediated patients, but is elevated compared with healthy controls (D). It is not possible to perform statistics with the Kruskal-Wallis test for the expression of IL-12, IL-4, and IL-13, because the respective cytokines are not expressed in healthy controls. ${ }^{*} P<0.05$, ** $P<0.01$. 
sponse, whereas Th2-mediated processes seem to be of less importance.

Both IMNM and nIMNM have in common the presence of a dominant necrotizing component with myophagocytosis, which is by far less prominent in PM and DM. Furthermore, specific ultrastructural alterations, such as tubuloreticular inclusions, which may be found in DM and rarely in other inflammatory myopathies (eg, HIV- or lupus erythematodes-associated myositis), are not a characteristic feature of IMNM or nIMNM. The use of MHC class $I$ and MAC and staining for $T$ and $B$ lymphocytes are of further discriminating value. These markers, in concert with staining of diverse membrane proteins, may also help to differentiate these entities from, for example, limbgirdle muscular dystrophies and dystrophinopathies, because the latter entities may also reveal inflammatory cells. $^{2,51}$ In IMNM, the identification of a significant amount of $\mathrm{CD}_{4}^{+}$and $\mathrm{CD} 8^{+} \mathrm{T}$ cells, grouped in the endomysial and perimysial compartment, and a strong and ubiquitous up-regulation of MHC class I molecules on the sarcolemma and MAC deposition on endomysial capillaries in most biopsy specimens support the diagnosis of an immune-mediated process. In contrast, nIMNMs with a toxic cause do not show a significant T- or B-cellular infiltrate, and sarcolemmal MHC class I expression is generally low, as is MAC deposition on capillaries. Some specimens of either subgroup did not differ significantly in these parameters and, therefore, clinical and laboratory results, especially measurements of myositis-specific and myositis-associated antibodies, are helpful; additional molecular analysis by GPCR of IFN- $\gamma$, TNF- $\alpha$, IL-12, and STAT1 may further increase diagnostic accuracy in individual patients.

The expression of MHC class I molecules in IMNM has been assessed, with divergent results in different studies. Although some researchers found at least some sarcolemmal MHC class I expression, ${ }^{19,38}$ others have not. ${ }^{27}$ More important, the absence of perifascicular atrophy, evidenced in MHC class I preparations in IMNM, is in line with previous studies. ${ }^{27,52}$ In statin-induced NMs with HMG-CoA autoantibodies, up-regulation of sarcolemmal $\mathrm{MHC}$ class I is described as a valuable diagnostic tool. ${ }^{26,29,53}$ Furthermore, Karpati et $\mathrm{al}^{54}$ have described MHC class I expression on regenerating fibers in patients with muscular dystrophy and also studied several groups of IIMs, showing a specific pattern of sarcolemmal and partial sarcoplasmic expression of the protein. Similar findings were reported at approximately the same time by McDouall et al. ${ }^{55}$

Although some authors note complement (MAC) deposition on a few capillaries, others describe the absence of any MAC immunoreactivity in their IMNM biopsy specimens. ${ }^{6,28,38}$ Interestingly, the previously described pronounced MAC deposition on significantly thickened pipestem capillaries associated with necrotizing myopathy ${ }^{32}$ is rarely seen among IMNM biopsy specimens in general, and the character of MAC deposition in these cases and the one in DM is clearly different. ${ }^{1,4}$ The relevance of MAC staining in paraneoplastic myopathies has been underlined on several occasions. ${ }^{33,34,56}$ Strong capillary MAC deposition in our three specimens with a paraneo- plastic cause follows the reported characteristics. In summary, MAC deposition and expression of sarcolemmal MHC class I in IMNM clearly reveal a distinct pattern compared with DM; in addition, middle-sized vessels are targeted by the immune response, ${ }^{1}$ and undulating tubules are regularly found by ultrastructural investigation.

A hallmark of IMNM, described in nearly all reports, is the relative paucity of inflammatory infiltrates; however, there is no specification about which cells are relatively rare. ${ }^{3,19,20,27,28,38,56,57}$ In our series of IMNM biopsy specimens, the lymphocytic infiltrate was less pronounced than in highly active DM, IBM, or PM; however, also in these entities, considerable variation concerning the density of lymphocytes exists and is well-known in daily routine. At variance with many reports, we have identified a significant endomysial infiltrate consisting of $\mathrm{CD}^{+} \mathrm{T}$ cells, $\mathrm{CD}^{+}$cells, and few B cells in our IMNM biopsy series, which were pronounced, for instance, in biopsy specimens from patients with antisynthetase syndrome. In IMNM, CD8 ${ }^{+} \mathrm{T}$ cells are frequently found in association with myophagocytosis, but their focal accumulation, as seen in PM or IBM, is not present. The endomysial distribution of the infiltrate, sometimes combined with a perivascular accumulation in conjunction with large areas of $\mathrm{MHC}$ class I up-regulation, strongly argues for a CD8-MHC class I-restricted immune component. $\mathrm{CD}^{+}{ }^{+} \mathrm{T}$ cells, $\mathrm{CD}^{+}$plasmacytoid dendritic cells, and T-helper cells have been studied extensively in $\mathrm{PM}$, IBM, and DM, ${ }^{11,44,58-62}$ demonstrating their pathogenic relevance in IIMs. Thus, the presence of a conspicuous lymphocytic infiltrate should always prompt for consideration of an immune-mediated cause of NM.

Because cytokines and chemokines orchestrate many aspects of the immune response, we have analyzed a comprehensive set of mediators involved in both the Th1M1- and the Th2-M2-mediated immune responses. We found a significant up-regulation of TNF- $\alpha$ in patients with IMNM compared with healthy control biopsy specimens in which this cytokine is expressed at low levels, as previously described. ${ }^{63-65}$ Given the overwhelming dominance of macrophages, we hypothesize that TNF- $\alpha$ expression can most likely be attributed to them. The important role of TNF- $\alpha$ in IIMs has been elegantly demonstrated, ${ }^{66,67}$ but has not been addressed in detail in necrotizing myopathies. In addition to TNF- $\alpha$, we have also found elevated levels of the proinflammatory cytokine IL-12, indicating an M1-biased immune response. Furthermore, we have observed a synergistic up-regulation of IFN- $\gamma$ and TNF- $\alpha$ in our specimens, underlining an active Th1-M1 response by the well-defined stimulatory effect of IFN- $\gamma$ by $\mathrm{CD}^{+}{ }^{+}$cells, leading to TNF- $\alpha$ production by effector cells, such as macrophages. High expression of the Th1 master cytokine, IFN- $\gamma$, as shown in IMNM specimens, strongly supports our results of the often ubiquitous trans-sarcolemmal up-regulation of MHC class I molecules in our series, because IFN- $\gamma$ and TNF- $\alpha$ are major inducers of the major histocompatibility complexes. ${ }^{68}$ Interestingly, in earlier reports, not much IFN- $\gamma$ has been described in IIMs. ${ }^{40,65,69}$ However, type I interferons play important parts in PM and DM. ${ }^{70-73}$ The expression of master cytokines of the Th2 response, such 
as $\mathrm{IL}-4$ and $\mathrm{IL}-13$, is low or barely detectable in both IMNM and nIMNM, which is in line with studies in PM, DM, and IBM. ${ }^{65,69}$ Markers of an alternative activation status of macrophages (M2), such as the mannose receptor (CD206), and the IL-4 receptor $\alpha$ (CD124) are not expressed at different levels in both groups.

We have identified three patients in the IMNM group displaying antisynthetase and anti-SRP autoantibodies, with few $B$ cells accompanied by high levels of CXCL13 expression, a chemoattractant of $B$ cells, which has also been recently observed in patients with juvenile $D M{ }^{74} B$ cells and B-cell chemokines have been identified by others, mainly in DM, and a potential for the development of new therapeutic targets has been noted. Thus, it is worth considering the possibility of $\mathrm{CD}_{2} \mathrm{O}^{+}$B-cell targeting agents, such as rituximab, B-cell activating factor belonging to the TNF family, or others. ${ }^{12,44,75}$ Rituximab has been administered in refractory IIMs and in IMNM with anti-SRP autoantibodies and antisynthetase syndrome, with some encouraging and some disappointing results. ${ }^{22,76-80}$ The rationale for use of this treatment, however, is theoretically well defined, but has not yet been supported by molecular data, as indicated herein. Given the fact that TNF- $\alpha$ was expressed at high levels in many specimens, TNF blockade may also be an alternative treatment approach in IMNM. Although in principle successful, TNF blockade has not consistently produced promising results in IIMs. ${ }^{41,81-83}$

Few data on targeted therapy as an alternative to standard corticosteroid treatment ${ }^{42,75}$ are available for IIM and for IMNM specifically, which have a presumed autoimmune etiopathogenesis in common. Yet, we believe that individual assessment of key cytokines and chemokines in IMNM muscle biopsy specimens, and in perspective also in the patients' blood, may provide useful biomarkers that can open new avenues for developments of a meaningful treatment.

\section{Acknowledgments}

We thank Alexandra Döser and Petra Matylewski for their technical support, Dr. Frank Hanisch (University of Halle, Germany) for providing a biopsy specimen of immunemediated necrotizing myopathy and corresponding clinical data, and Dr. Kelly Miller for critically reading the manuscript.

\section{References}

1. Pestronk A: Acquired immune and inflammatory myopathies: pathologic classification. Curr Opin Rheumatol 2011, 23:595-604

2. van der Meulen MF, Bronner IM, Hoogendijk JE, Burger $H$, van Venrooij WJ, Voskuyl AE, Dinant HJ, Linssen WH, Wokke $\mathrm{JH}$, de Visser M: Polymyositis: an overdiagnosed entity. Neurology 2003, 61:316-321

3. Bronner IM, Hoogendijk JE, Wintzen AR, van der Meulen MF, Linssen WH, Wokke JH, de Visser M: Necrotising myopathy, an unusual presentation of a steroid-responsive myopathy. J Neurol 2003, 250: 480-485

4. Liang C, Needham M: Necrotizing autoimmune myopathy. Curr Opin Rheumatol 2011, 23:612-619
5. Dalakas MC: Pathogenesis and therapies of immune-mediated myopathies. Autoimmun Rev 2012, 11:203-206

6. Benveniste O, Romero NB: Myositis or dystrophy? traps and pitfalls Presse Med 2011, 40:e249-e255

7. Dalakas MC: Immunotherapy of inflammatory myopathies: practical approach and future prospects. Curr Treat Options Neurol 2011, 13:311-323

8. Dalakas MC: Inflammatory myopathies: management of steroid resistance. Curr Opin Neurol 2011, 24:457-462

9. Dalakas MC, Rakocevic G, Schmidt J, Salajegheh M, McElroy B, Harris-Love MO, Shrader JA, Levy EW, Dambrosia J, Kampen RL, Bruno DA, Kirk AD: Effect of Alemtuzumab (CAMPATH 1-H) in patients with inclusion-body myositis. Brain 2009, 132(Pt 6):1536-1544

10. Dalakas MC, Sonies B, Dambrosia J, Sekul E, Cupler E, Sivakumar K: Treatment of inclusion-body myositis with IVIg: a double-blind, placebo-controlled study. Neurology 1997, 48:712-716

11. Greenberg SA, Bradshaw EM, Pinkus JL, Pinkus GS, Burleson T, Due B, Bregoli L, O'Connor KC, Amato AA: Plasma cells in muscle in inclusion body myositis and polymyositis. Neurology 2005, 65:17821787

12. Hak AE, de Paepe B, de Bleecker JL, Tak PP, de Visser M: Dermatomyositis and polymyositis: new treatment targets on the horizon. Neth J Med 2011, 69:410-421

13. Greenberg SA: Inflammatory myopathies: evaluation and management. Semin Neurol 2008, 28:241-249

14. Sultan SM, Isenberg DA: Re-classifying myositis. Rheumatology (Oxford) $2010,49: 831-833$

15. Khan S, Christopher-Stine L: Polymyositis, dermatomyositis, and autoimmune necrotizing myopathy: clinical features. Rheum Dis Clin North Am 2011, 37:143-158

16. Dalakas MC: Toxic and drug-induced myopathies. J Neurol Neurosurg Psychiatry 2009, 80:832-838

17. Mastaglia FL, Garlepp MJ, Phillips BA, Zilko PJ: Inflammatory myopathies: clinical, diagnostic and therapeutic aspects. Muscle Nerve 2003, 27:407-425

18. Mammen AL, Chung T, Christopher-Stine L, Rosen P, Rosen A, Casciola-Rosen LA: Autoantibodies against 3-hydroxy-3-methylglutaryl-coenzyme a reductase (HMGCR) in patients with statin-associated autoimmune myopathy. Arthritis Rheum 2011, 63:713-721

19. Miller T, Al-Lozi MT, Lopate G, Pestronk A: Myopathy with antibodies to the signal recognition particle: clinical and pathological features. J Neurol Neurosurg Psychiatry 2002, 73:420-428

20. Grable-Esposito P, Katzberg HD, Greenberg SA, Srinivasan J, Katz J, Amato AA: Immune-mediated necrotizing myopathy associated with statins. Muscle Nerve 2010, 41:185-190

21. Sadeh M, Dabby R: Steroid-responsive myopathy: immune-mediated necrotizing myopathy or polymyositis without inflammation? J Clin Neuromuscul Dis 2008, 9:341-344

22. Valiyil R, Casciola-Rosen L, Hong G, Mammen A, Christopher-Stine L: Rituximab therapy for myopathy associated with anti-signal recognition particle antibodies: a case series. Arthritis Care Res (Hoboken) 2010, 62:1328-1334

23. Needham M, Fabian V, Knezevic W, Panegyres P, Zilko P, Mastaglia FL: Progressive myopathy with up-regulation of MHC-I associated with statin therapy. Neuromuscul Disord 2007, 17:194-200

24. Gunawardena H, Betteridge ZE, McHugh NJ: Myositis-specific autoantibodies: their clinical and pathogenic significance in disease expression. Rheumatology (Oxford) 2009, 48:607-612

25. Mammen AL: Dermatomyositis and polymyositis: clinical presentation, autoantibodies, and pathogenesis. Ann N Y Acad Sci 2010, 1184:134-153

26. Christopher-Stine L, Casciola-Rosen LA, Hong G, Chung T, Corse AM, Mammen AL: A novel autoantibody recognizing 200-kd and $100-k d$ proteins is associated with an immune-mediated necrotizing myopathy. Arthritis Rheum 2010, 62:2757-2766

27. Hengstman GJ, ter Laak HJ, Vree Egberts WT, Lundberg IE, Moutsopoulos HM, Vencovsky J, Doria A, Mosca M, van Venrooij WJ, van Engelen BG: Anti-signal recognition particle autoantibodies: marker of a necrotising myopathy. Ann Rheum Dis 2006, 65:1635-1638

28. Kao AH, Lacomis D, Lucas M, Fertig N, Oddis CV: Anti-signal recognition particle autoantibody in patients with and patients without idiopathic inflammatory myopathy. Arthritis Rheum 2004, 50:209-215

29. Mammen AL, Chung T, Christopher-Stine L, Rosen $P$, Rosen $A$, Doering KR, Casciola-Rosen LA: Autoantibodies against 3-hydroxy- 
3-methylglutaryl-coenzyme A reductase in patients with statin-associated autoimmune myopathy. Arthritis Rheum 2011, 63: 713-721

30. Ghirardello A, Rampudda M, Ekholm L, Bassi N, Tarricone E, Zampieri S, Zen M, Vattemi GA, Lundberg IE, Doria A: Diagnostic performance and validation of autoantibody testing in myositis by a commercial line blot assay. Rheumatology (Oxford) 2010, 49:2370-2374

31. Hirakata M: Autoantibodies to aminoacyl-tRNA synthetases. Intern Med 2005, 44:527-528

32. Emslie-Smith AM, Engel AG: Necrotizing myopathy with pipestem capillaries, microvascular deposition of the complement membrane attack complex (MAC), and minimal cellular infiltration. Neurology 1991, 41:936-939

33. Sampson JB, Smith SM, Smith AG, Singleton JR, Chin S, Pestronk A Flanigan KM: Paraneoplastic myopathy: response to intravenous immunoglobulin. Neuromuscul Disord 2007, 17:404-408

34. Levin MI, Mozaffar T, Al-Lozi MT, Pestronk A: Paraneoplastic necrotizing myopathy: clinical and pathological features. Neurology 1998 , 50:764-767

35. Suber TL, Casciola-Rosen L, Rosen A: Mechanisms of disease: autoantigens as clues to the pathogenesis of myositis. Nat Clin Pract Rheumatol 2008, 4:201-209

36. Mastaglia FL, Needham M: Update on toxic myopathies. Curr Neuro Neurosci Rep 2012, 12:54-61

37. Prokop S, Heppner FL, Goebel HH, Stenzel W: M2 polarized macrophages and giant cells contribute to myofibrosis in neuromuscular sarcoidosis. Am J Pathol 2011, 178:1279-1286

38. Dimitri D, Andre C, Roucoules J, Hosseini H, Humbel RL, Authier FJ: Myopathy associated with anti-signal recognition peptide antibodies: clinical heterogeneity contrasts with stereotyped histopathology. Muscle Nerve 2007, 35:389-395

39. Banwell BL, Engel AG: AlphaB-crystallin immunolocalization yields new insights into inclusion body myositis. Neurology 2000, 54:10331041

40. Tews DS, Goebel HH: Cytokine expression profile in idiopathic inflammatory myopathies. J Neuropathol Exp Neurol 1996, 55:342-347

41. Labioche I, Liozon E, Weschler B, Loustaud-Ratti V, Soria P, Vidal E: Refractory polymyositis responding to infliximab: extended follow-up. Rheumatology (Oxford) 2004, 43:531-532

42. Choy EH, Hoogendijk JE, Lecky B, Winer JB: Immunosuppressant and immunomodulatory treatment for dermatomyositis and polymyositis. Cochrane Database Syst Rev 2005, (3):CD003643

43. Shi K, Hayashida K, Kaneko M, Hashimoto J, Tomita T, Lipsky PE, Yoshikawa H, Ochi T: Lymphoid chemokine B cell-attracting chemokine-1 (CXCL13) is expressed in germinal center of ectopic lymphoid follicles within the synovium of chronic arthritis patients. J Immunol 2001, 166:650-655

44. De Paepe B, Creus KK, De Bleecker JL: Role of cytokines and chemokines in idiopathic inflammatory myopathies. Curr Opin Rheumatol 2009, 21:610-616

45. Aloisi F, Columba-Cabezas S, Franciotta D, Rosicarelli B, Magliozzi R, Reynolds R, Ambrosini E, Coccia E, Salvetti M, Serafini B: Lymphoid chemokines in chronic neuroinflammation. J Neuroimmunol 2008, 198:106-112

46. Gordon S, Taylor PR: Monocyte and macrophage heterogeneity. Nat Rev Immunol 2005, 5:953-964

47. Lumeng CN, Bodzin JL, Saltiel AR: Obesity induces a phenotypic switch in adipose tissue macrophage polarization. J Clin Invest 2007 117:175-184

48. Martinez FO, Helming L, Gordon S: Alternative activation of macrophages: an immunologic functional perspective. Annu Rev Immunol 2009, 27:451-483

49. Murray PJ, Wynn TA: Obstacles and opportunities for understanding macrophage polarization. J Leukoc Biol 2011, 89:557-563

50. Galli SJ, Borregaard N, Wynn TA: Phenotypic and functional plasticity of cells of innate immunity: macrophages, mast cells and neutrophils. Nat Immunol 2011, 12:1035-1044

51. Dalakas MC: Polymyositis, dermatomyositis and inclusion-body myositis. N Engl J Med 1991, 325:1487-1498

52. Takada T, Hirakata M, Suwa A, Kaneko Y, Kuwana M, Ishihara T, Ikeda Y: Clinical and histopathological features of myopathies in Japanese patients with anti-SRP autoantibodies. Mod Rheumatol 2009, 19:156-164
53. Mammen AL: Autoimmune myopathies: autoantibodies, phenotypes and pathogenesis. Nat Rev Neurol 2011, 7:343-354

54. Karpati G, Pouliot Y, Carpenter S: Expression of immunoreactive major histocompatibility complex products in human skeletal muscles. Ann Neurol 1988, 23:64-72

55. McDouall RM, Dunn MJ, Dubowitz V: Expression of class I and class II MHC antigens in neuromuscular diseases. J Neurol Sci 1989, 89:213-226

56. Wegener S, Bremer J, Komminoth $\mathrm{P}$, Jung HH, Weller M: Paraneoplastic necrotizing myopathy with a mild inflammatory component: a case report and review of the literature. Case Rep Oncol 2010, 3:88-92

57. Hoogendijk JE, Amato AA, Lecky BR, Choy EH, Lundberg IE, Rose MR, Vencovsky J, de Visser M, Hughes RA: 119th ENMC international workshop: trial design in adult idiopathic inflammatory myopathies, with the exception of inclusion body myositis, 10-12 October 2003, Naarden, The Netherlands. Neuromuscul Disord $2004,14: 337-345$

58. Greenberg SA, Pinkus GS, Amato AA, Pinkus JL: Myeloid dendritic cells in inclusion-body myositis and polymyositis. Muscle Nerve 2007, 35:17-23

59. Hohlfeld R, Engel AG, li K, Harper MC: Polymyositis mediated by T lymphocytes that express the gamma/delta receptor. $\mathrm{N}$ Engl J Med 1991, 324:877-881

60. Hohlfeld R, Dornmair K: Revisiting the immunopathogenesis of the inflammatory myopathies. Neurology 2007, 69:1966-1967

61. Page G, Chevrel G, Miossec P: Anatomic localization of immature and mature dendritic cell subsets in dermatomyositis and polymyositis: interaction with chemokines and Th1 cytokine-producing cells. Arthritis Rheum 2004, 50:199-208

62. Page G, Sattler A, Kersten S, Thiel A, Radbruch A, Miossec P: Plasma cell-like morphology of Th1-cytokine-producing cells associated with the loss of CD3 expression. Am J Pathol 2004, 164:409-417

63. Tateyama M, Nagano I, Yoshioka M, Chida K, Nakamura S, Itoyama $Y$ : Expression of tumor necrosis factor-alpha in muscles of polymyositis. J Neurol Sci 1997, 146:45-51

64. Lindberg C, Oldfors A, Tarkowski A: Local T-cell proliferation and differentiation in inflammatory myopathies. Scand J Immunol 1995, 41:421-426

65. Lundberg I, Brengman JM, Engel AG: Analysis of cytokine expression in muscle in inflammatory myopathies, Duchenne dystrophy, and non-weak controls. J Neuroimmunol 1995, 63:9-16

66. Kuru S, Inukai A, Liang Y, Doyu M, Takano A, Sobue G: Tumor necrosis factor-alpha expression in muscles of polymyositis and dermatomyositis. Acta Neuropathol 2000, 99:585-588

67. De Bleecker JL, Meire VI, Declercq W, Van Aken EH: Immunolocalization of tumor necrosis factor-alpha and its receptors in inflammatory myopathies. Neuromuscul Disord 1999, 9:239-246

68. Eloranta ML, Barbasso Helmers S, Ulfgren AK, Ronnblom L, Alm GV, Lundberg IE: A possible mechanism for endogenous activation of the type I interferon system in myositis patients with antiJo-1 or anti-Ro 52/anti-Ro 60 autoantibodies. Arthritis Rheum 2007, 56:3112-3124

69. Lepidi H, Frances V, Figarella-Branger D, Bartoli C, Machado-Baeta A, Pellissier JF: Local expression of cytokines in idiopathic inflammatory myopathies. Neuropathol Appl Neurobiol 1998, 24:73-79

70. Greenberg SA, Sanoudou D, Haslett JN, Kohane IS, Kunkel LM, Beggs $\mathrm{AH}$, Amato AA: Molecular profiles of inflammatory myopathies. Neurology 2002, 59:1170-1182

71. Niewold TB, Kariuki SN, Morgan GA, Shrestha S, Pachman LM: Elevated serum interferon-alpha activity in juvenile dermatomyositis: associations with disease activity at diagnosis and after thirty-six months of therapy. Arthritis Rheum 2009, 60:1815-1824

72. Bilgic H, Ytterberg SR, Amin S, McNallan KT, Wilson JC, Koeuth T, Ellingson S, Newman B, Bauer JW, Peterson EJ, Baechler EC, Reed AM: Interleukin-6 and type I interferon-regulated genes and chemokines mark disease activity in dermatomyositis. Arthritis Rheum 2009, 60:3436-3446

73. Salajegheh M, Kong SW, Pinkus JL, Walsh RJ, Liao A, Nazareno R, Amato AA, Krastins B, Morehouse C, Higgs BW, Jallal B, Yao Y, Sarracino DA, Parker KC, Greenberg SA: Interferon-stimulated gene 15 (ISG15) conjugates proteins in dermatomyositis muscle with perifascicular atrophy. Ann Neurol 2010, 67:53-63

74. Lopez De Padilla CM, Vallejo AN, Lacomis D, McNallan K, Reed AM Extranodal lymphoid microstructures in inflamed muscle and disease severity of new-onset juvenile dermatomyositis. Arthritis Rheum 2009, 60: 1160-1172 
75. Dalakas MC: Immunotherapy of myositis: issues, concerns and future prospects. Nat Rev Rheumatol 2010, 6:129-137

76. Arlet JB, Dimitri D, Pagnoux C, Boyer O, Maisonobe T, Authier FJ, Bloch-Queyrat C, Goulvestre C, Heshmati F, Atassi M, Guillevin L, Herson S, Benveniste O, Mouthon L: Marked efficacy of a therapeutic strategy associating prednisone and plasma exchange followed by rituximab in two patients with refractory myopathy associated with antibodies to the signal recognition particle (SRP). Neuromuscul Disord 2006, 16:334-336

77. Rios Fernandez R, Callejas Rubio JL, Sanchez Cano D, Saez Moreno JA, Ortego Centeno N: Rituximab in the treatment of dermatomyositis and other inflammatory myopathies: a report of 4 cases and review of the literature. Clin Exp Rheumatol 2009, 27:1009-1016

78. Whelan BR, Isenberg DA: Poor response of anti-SRP-positive idiopathic immune myositis to B-cell depletion. Rheumatology (Oxford) 2009, 48:594-595
79. Sem M, Molberg O, Lund MB, Gran JT: Rituximab treatment of the anti-synthetase syndrome: a retrospective case series. Rheumatology (Oxford) 2009, 48:968-971

80. Zong $\mathrm{M}$, Lundberg IE: Pathogenesis, classification and treatment of inflammatory myopathies. Nat Rev Rheumatol 2011, 7:297-306

81. Riley P, McCann LJ, Maillard SM, Woo P, Murray KJ, Pilkington CA: Effectiveness of infliximab in the treatment of refractory juvenile dermatomyositis with calcinosis. Rheumatology (Oxford) 2008, 47: 877-880

82. Hengstman GJ, van den Hoogen FH, van Engelen BG: Treatment of dermatomyositis and polymyositis with anti-tumor necrosis factoralpha: long-term follow-up. Eur Neurol 2004, 52:61-63

83. Hengstman GJ, van den Hoogen FH, Barrera P, Netea MG, Pieterse $A$, van de Putte LB, van Engelen BG: Successful treatment of dermatomyositis and polymyositis with anti-tumor-necrosis-factor-alpha: preliminary observations. Eur Neurol 2003, 50:10-15 